\title{
CULTURAL TOURISM IN PUNJAB, PAKISTAN
}

\author{
Qamar Farooq
}

\author{
Research Scholar, ZJGSU, Hangzhou, China \\ Najma Bano, NCA, Multan \\ Yanni Zhang, ZJGSU, Hangzhou, China
}

Salma Tehseen, M.C School, Ramzanabad, Mutltan, NCA, Multan

qamarfarooq@pop.zjgsu.edu.cn

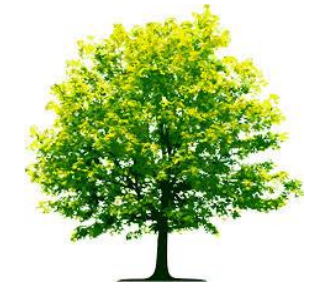

Keywords: Tourism Industry, expansion of Tourism, Cultural Awareness.

\begin{abstract}
A B S T RA C T
The tourism industry is flourishing with a rapid pace. A wide expansion in tourism sector all over the world has been observed in last 30 years. Pakistan is one of the countries where tourists like to visit mountains, valleys and beautiful natural places especially in northern areas. Tourists from different countries have diverse interests and likings. One category of tourists consists of those people who are fond of cultural awareness. People need cultural awareness for remaining successful in different cultures (Farooq, 2016).Cross-cultural management has been hypothesized as vital moderator in relationship of important variables (Hao et al., 2018). Hence, cultural tourism is also of prime importance. There are so many places in Pakistan which are culturally famous. Unfortunately, many people mingle culture and history gratuitously. Although, history and historical places represent cultural facet of ages but contemporary representations are also manifestation of culture of a society or nation.
\end{abstract}

Citation: Qamar Farooq (2018). Cultural Tourism In Punjab,Pakistan. International Journal of Advanced Multidisciplinary Scientific Research (IJAMSR ) ISSN:2581-4281 Vol 1, Issue 5, July, 2018, \#Art.514, pp 18-22

\section{Introduction}

The tourism industry is flourishing with a rapid pace. A wide expansion in tourism sector all over the world has been observed in last 30 years. Pakistan is one of the countries where tourists like to visit mountains, valleys and beautiful natural places especially in northern areas. Tourists from different countries have diverse interests and likings. One category of tourists consists of those people who are fond of cultural awareness. People need cultural awareness for remaining successful in different cultures (Farooq, 2016).Cross-cultural management has been hypothesized as vital moderator in relationship of important variables (Hao et al., 2018). Hence, cultural tourism is also of prime importance. There are so many places in Pakistan, which are culturally famous. 


\section{International Journal of Advanced Multidisciplinary Scientific Research (IJAMSR) ISSN:2581-4281}

Unfortunately, many people mingle culture and history gratuitously. Although, history and historical places represent cultural facet of ages but contemporary representations are also manifestation of culture of a society or nation.

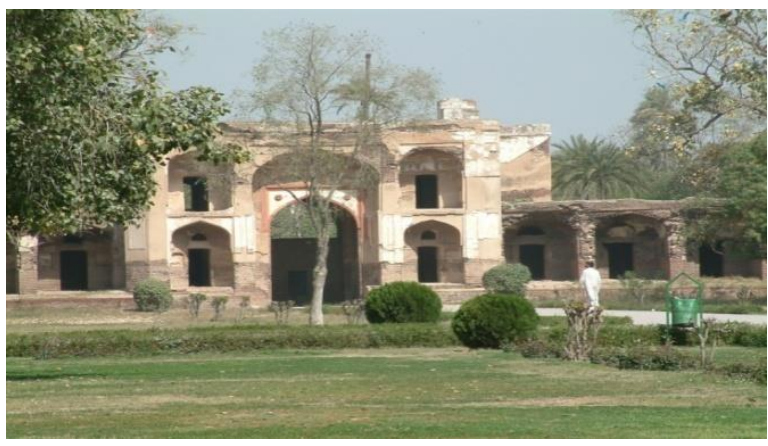

Beautiful Sites of Punjab

\section{Global Creative Industry}

Creative industry is the emerging concept wherein link of culture has been broadly explained (Craik, 2014). This indicates to the extended scope of cultural perspective in global creative industries. Since there is a variety of relationships between cultural industries and cultural policy (Hesmondhalgh and Pratt, 2005), this paper is aimed to determine the need of endeavors and policies to outline the places of cultural importance in most thickly populated province of Pakistan. This paper will be a smart guide for those potential tourists who are interested in cultural tourism in Pakistan.

Ranging from the diversity of four provinces of Pakistan to the most famous cultural places, cultural tourism in Pakistan is expected to lead to a matchless creative industry which will soon assume the global recognition. To support this, Pakistan Tourism Development Corporation (PTDC) is a public corporation which was formed in 1970 for development of tourism activities in
Pakistan especially for the facilitation of the foreigners. Centered in Islamabad, the Corporation is working with its four subsidiaries for projection of tourism. PTDC is successful in attaining its corporate objectives up to a great extent. However, there is still room of focus for cultural tourism by creative industry for providing new dimensions to the potential tourists particularly interested in awareness of cultural differences. This area is also relevant to those entities which are catalysts towards bridging the cultural distances among nations and those who want to contribute in cross cultural management and cross cultural harmony.

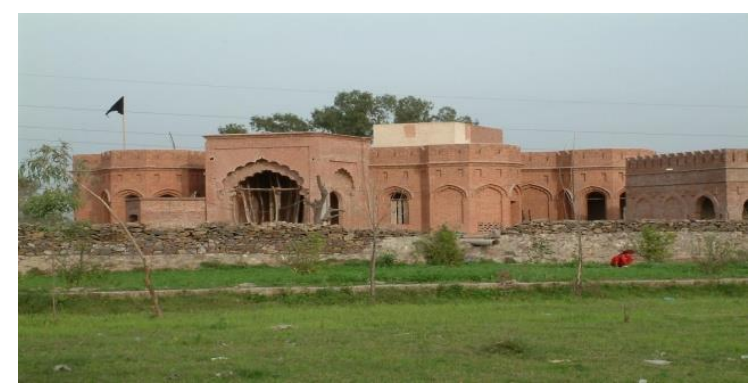

Cultural Site

\section{Cultural Tourism in Pakistan}

Though Pakistan appeared as a sovereign state in 1947 but its culture stems from the ancients, especially world famous Gandhara Art originated in the area of Swat and Peshawar Valley hundreds years ago. Among many famous archaeological sites, two are very famous in Pakistan with predominant identification. Different parameters of Pakistani culture include its ethnic groups, literature, poetry, music, dances, painting, architecture, cuisines, languages, religion, dress, festivals and observations. As far as the religion is concerned, Pakistan is the first region of south Asia with full impact of Islam (Basham, 1965). Despite of several allegations of extremism, majority of Pakistani people are 


\section{International Journal of Advanced Multidisciplinary Scientific Research (IJAMSR) ISSN:2581-4281}

hospitable by culture. There are wonderful places in Pakistan which are not only beautiful but also unique in cultural perspective. True understanding of insight especially of festivals and observations of Pakistani culture demands cultural spot visits. A large number of tourists from different places of world visit eye-catching spots and places including valleys, mountains, mosques and archaeological sites. Specification of interesting cultural sites of Pakistan is worth-mentioning for prospective tourists. We present 5 sites of cultural importance in Punjab province of Pakistan with the recommendation that international tourists ::;dfdrrrro9f04aBBshould plan their cultural tour to Punjab, Pakistan.

First interesting place is located in Lahore known as Shalimar fort which is the exhibition of artistic and aesthetic skills and culture when Mughal Empire was on its zenith (Quraeshi, 2017). The construction of garden was started in $17^{\text {th }}$ century and was completed in one and a half year. Shalimar garden was built by Mughals to entertain royal guests. The design of garden is of Persian style CHARBAGH. One of the important features of Shalimar garden is water feature as it contains 410 fountains which are called HAUZ. There are a large number of trees including 14 types of useable fruit trees. These fruit trees include peach, apple, apricot, cherry, plum, mango, orange and other fruits. In 1981, under UNESCO convention, the fort was included as a UNESCO World Heritage Site.

Shalimar Garden

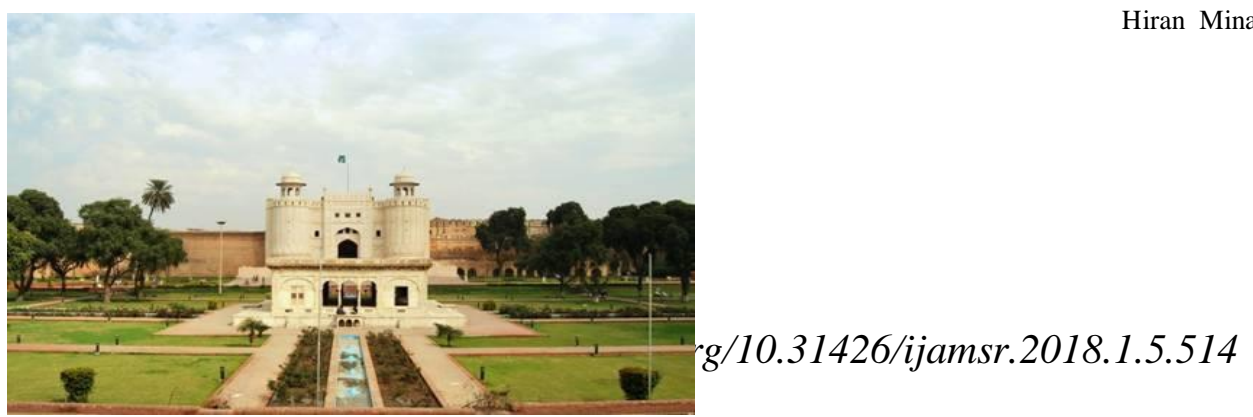

Next is HiranMinar, named for deer tower. HiranMinaris also a cultural representation of Mughal Empire. The complex was built in $17^{\text {th }}$ century in the honor of Jehangir's beloved pet antelope which shows the Mughal's culture and relationship between pets and hunting(Brown and Hutton, 2012). The reserve at this place was built to allow Mughal emperors to experience the sense of semi-wildness for hunting.HiranMinar is the masterpiece of art and culture of Mughlia reign. Between different complexes, hydraulics complex has two important features; grave of antelope and water collection system which is distinctive in its form. The name of antelope was Mansiraj and he was famous to lure the wild animals to the tank for the hunt of emperor (Brown and Hutton, 2012). Mughal family was famous to spend time and resources for satisfaction of their fondness and this became the tradition and culture in centuries old reign of the Mughal emperor.

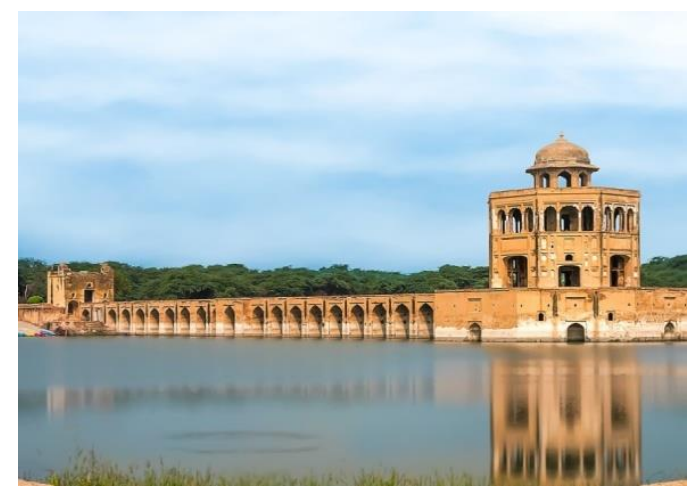

Hiran Minar 
https://doi.org/10.31426/ijamsr.2018.1.5.514

I J A M S R

\section{International Journal of Advanced Multidisciplinary Scientific Research (IJAMSR) ISSN:2581-4281}

Next ithe tombmb of Shah Rukn-e-Alam. Sheikh Rukn Uddin AbulFateh known as Shah Rukn e Alam was a famous Sufi saint in the area of Multan. He was grandson of BahauddinZakariya who was also an eminent Sufi. The first university of Multan, BahauddinZakariya University was established after his name. This shows that how educational institutions are associated with cultural perspectives of the area. Rukn-eAlam was buried in the Mausoleum, now a famous site for hundred thousands of pilgrims from all over the Asia. The USESCO World Heritage Site is keeping this tomb on the tentative list. A daily train, named after Shah Rukn e alarm is operated between Multan station and Karachi station. The location where his tomb is situated is called QillaKohnaQasimBagh usually renowned with the short title Qilla. This Qilla exhibits the belief and culture of the majority of the inhabitants of the area who not only respect the Sufis and Saints, but also have the creeds about their spiritual satisfaction on pilgrims at his tomb. For international tourists, the site is open for a visit and to have a cultural view of the number of pilgrims visiting the tomb on a daily basis.

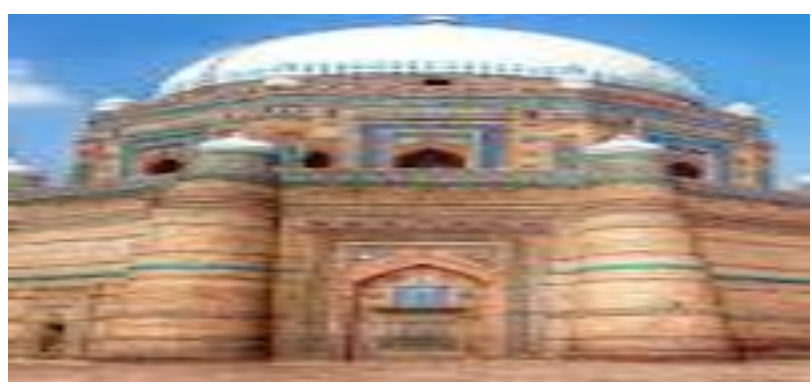

MultaniQlla
Islam and Muslim culture are closely related with each other. One more beautiful memory of the Mughal's reign is the Badshahi Mosque situated near Lahore Fort. This mosque was commissioned by Emperor Aurangzeb and its construction was completed in 2 year duration. As another big example of Mughal architecture, Badshahi Mosque is currently second largest mosque of Pakistan(Meri and Bacharach, 2006). Location of Lahore was very important as it was considered as a strategic point, preventing the invade especially from the west side. This is why, Badshashi mosque had been used as the military garrison by Mughals, Sikh Army and British Rule. It has a museum which also contains a lot of things giving the cultural expression. This mosque is the site of attraction for foreigners visiting Lahore. Great national poet of Pakistan, Dr. Muhammad Iqbal is buried in the side of this mosque and it has the status of national honor with guards deputed on duty at the tomb of Dr. Muhammad Iqbal. Courtyard of the mosque has the capacity to accommodate 100,000 worshipers.

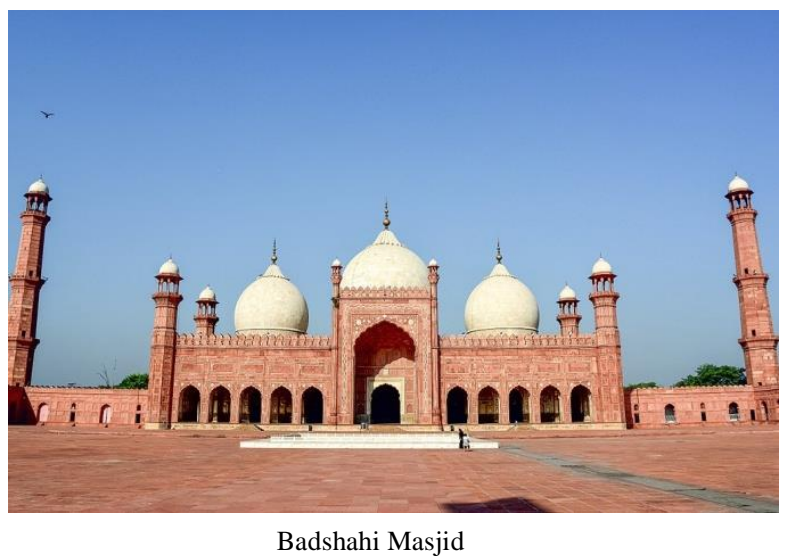


https://doi.org/10.31426/ijamsr.2018.1.5.514

I J A M S R

\section{International Journal of Advanced Multidisciplinary Scientific Research (IJAMSR) ISSN:2581-4281}

Last cultural site in our article is Harappa which shows 6000 BC Indus valley civilization, the urban culture. The measures and weights of this civilization were extensively standardized. Harappa is categorized by differentiated living style, fortified religious centers and flat roofed brick houses. The commonly used metals were copper and bronze. Harappans had many trade roots used for merchandising valuable things. About $15.5 \%$ injuries in human skeletal remains show that the Harappans were not totally peaceful (Schugabcd, 2012). Visit of Harappa gives an imagination of culture and lifestyle of people living thousands years ago.

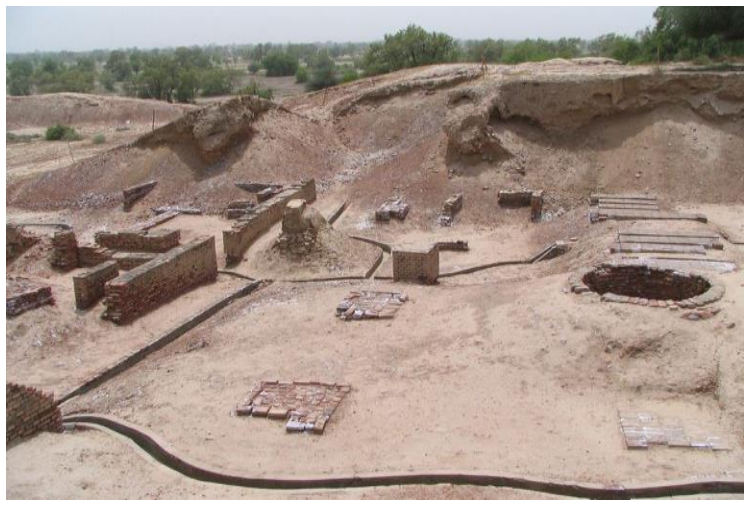

Harappa

\section{Conclusion}

Tourists from different countries like to visit historical and beautiful places in Pakistan. Cultural tours are the main focus of those people who have primacy of cultural understanding. I recommend these people to visit these 5 sites having cultural importance in Punjab. There are many other sites which can still be explored and brought under consideration for the readers and visitors.

\section{References}

1) BASHAM, A. L. 1965. Kingship and Community in Ancient India. by Charles Drekmeier. Pacific Affairs, 37, 225.

2) BROWN, R. M. \& HUTTON, D. S. 2012. 1. Revisiting "Asian Art”, Wiley-Blackwell.

3) CRAIK, J. 2014. Cultural Policy: Management, Value and Modernity in the Creative Industries Dave O'Brien (Routledge, London and New York, 2014, ISBN 978-0-415-81759-2 (hbk, 166 pp.)). Australian Journal of Public Administration, 73, 149-150.

4) FAROOQ, Q. 2016. Impact of Cross Cultural Training on Perceived Success of Expatriates.

5) HAO, Y., FAROOQ, Q. \& SUN, Y. 2018. Development of theoretical framework and measures for the role of social media in realizing corporate social responsibility through native and non-native communication modes: Moderating effects of crosscultural management. Corporate Social Responsibility \& Environmental Management.

6) HESMONDHALGH, D. \& PRATT, A. C. 2005. Cultural industries and cultural policy. International Journal of Cultural Policy, 11, 1-13.

7) MERI, J. W. \& BACHARACH, J. L. 2006. Medieval Islamic Civilization: An Encyclopedia. Routledge Encyclopedias of the Middle Ages.

8) QURAESHI, S. Harvest, Delight and Memory: Lessons of Lahore's Shalimar Gardens. Places: Forum of Design for the Public Realm, 2017.

9) SCHUGABCD, G. R. 2012. A peaceful realm? Trauma and social differentiation at Harappa. International Journal of Paleopathology, 2, 136-147. 